\title{
Study on the Influence of Particle Size and Grade of Total Tailings on the Fluidity of High-Concentration Filling Slurry considering Strength
}

\author{
Xiaobo Duan $\mathbb{D}^{1,2}$ Yucheng Huang, ${ }^{1}$ and Wenxiang Zheng ${ }^{2}$ \\ ${ }^{1}$ China University of Mining \& Technology, Beijing 100083, China \\ ${ }^{2}$ Inner Mongolia University of Science and Technology, Inner Mongolia, Baotou 014010, China \\ Correspondence should be addressed to Xiaobo Duan; bslx25@163.com
}

Received 15 September 2020; Revised 25 January 2021; Accepted 15 April 2021; Published 4 May 2021

Academic Editor: Dayang Xuan

Copyright ( 2021 Xiaobo Duan et al. This is an open access article distributed under the Creative Commons Attribution License, which permits unrestricted use, distribution, and reproduction in any medium, provided the original work is properly cited.

\begin{abstract}
To find out the effect of total tailing particle size and grading on the rheological property of filling slurry with high concentration, especially in high intensity, the experiment on the particle size of total tailings was conducted firstly to get the corresponding result. Then, the collapse test of mixed slurry with different cement tailing ratios and different concentrations was carried out to get the corresponding slump value and extension value. Furthermore, the rotational viscometer was applied to test shear stress in the samples with different cement tailing ratios and different concentrations, from which the relevant rheological parameter can be achieved through the Bingham rheological model. Finally, a strength test to mixed slurry block with different cement tailing ratios and different concentrations was conducted (3 days, 7 days, and 28 days); the corresponding intensity values were taken. The experiment result illustrates that with the increase of concentration and cement tailing ratio of the slurry, the collapse degree and extended degree of slurry decreased, while yield stress, plastic viscosity, and strength increased. When the concentration was raised from $70 \%$ to $72 \%$, all parameters that characterize good fluidity reduced obviously. As a result, the mixed slurry with a concentration of $70 \%$ and cement tailing ratio of $1: 8$ not only meets the requirements of production intensity but also has good mobility and low pipeline wear.
\end{abstract}

\section{Introduction}

With the rapid development of society and industry, the output and consumption of energy and mineral resource increase by leaps and bounds. The exploit to the mine with a well-buried condition has drawn to a close, while the orebodies buried deeply and with a complex structure has become the main part of modern mining [1-7]. However, the complicated and special geological buried condition is the big challenge in exploitation. At the same time, the huge amount of mineral production waste, including tailings, gob, and gangue, built up on the surface of the earth, which not only leads to the occupation of land resources but also results in geologic hazard, such as dam break and collapse [8-12]. Therefore, to enhance the output and recovery rate of the mineral source in the safe condition and decrease ore dilu- tion rate, it is effective to carry out the filling mining method, which can make full use of various industrial wastes as the filler of goaf to control roof strata, prevent ground from depression, and practice environment friendly concept [13-19].

However, the manufacturing technique of filling mining is complex. On the one hand, the hydration reaction of the gel material can produce a lot of heat in the preparation process of the filling slurry. On the other hand, the intensity of the hydration reaction is different, which leads to the undetermined content of the fine particle. Meanwhile, the preparation and pipeline flow process of the slurry is a thermalhydraulic-mechanical coupling behavior. The strength, integrity, and stability of solidified slurry after filling into goaf result from this behavior. At the same time, the cost of filling manufacture is high, which accounts for more than one-third 
TABLE 1: Physical and chemical properties of total tailings.

\begin{tabular}{|c|c|c|c|c|c|c|c|c|c|c|}
\hline \multicolumn{4}{|c|}{ Physical characteristic parameters } & \multicolumn{7}{|c|}{ Chemical composition (\%) } \\
\hline Relative density & $\begin{array}{l}\text { Loose density } \\
\qquad\left(\mathrm{t} / \mathrm{m}^{3}\right)\end{array}$ & $\begin{array}{l}\text { Dense density } \\
\left(t / \mathrm{m}^{3}\right)\end{array}$ & $\begin{array}{l}\text { Porosity } \\
(\%)\end{array}$ & $\begin{array}{c}\omega \\
\left(\mathrm{SiO}_{2}\right)\end{array}$ & $\begin{array}{c}\omega \\
\left(\mathrm{Al}_{2} \mathrm{O}_{3}\right)\end{array}$ & $\begin{array}{c}\omega \\
(\mathrm{CaO})\end{array}$ & $\begin{array}{c}\omega \\
(\mathrm{MgO})\end{array}$ & $\begin{array}{c}\omega \\
\left(\mathrm{Fe}_{2} \mathrm{O}_{3}\right)\end{array}$ & $\begin{array}{c}\omega \\
\text { (other) }\end{array}$ & $\begin{array}{l}\omega \\
(\mathrm{S})\end{array}$ \\
\hline 2.84 & 1.308 & 1.641 & 41.11 & 67.02 & 5.13 & 6.31 & 3.22 & 4.41 & 13.8 & 0.11 \\
\hline
\end{tabular}

of the whole exploitation cost. Therefore, it has become the hotspot in filling mining research to improve filling efficiency while ensuring backfill strength, keep stable operation of filling system, and reduce filling mining production cost [20-23]. Aimed at the problem that filling slurry with high concentration failed to fill the pipeline, Huang et al. [24] has conducted the research and found out that the filling slurry was snapped at the top of the drill hole resulting in a series of problems, such as "water hammer" impact during transportation, erosive ware to the inner wall of pipeline, pipeline vibration, filling slurry blocking, and even damage to the filling pump. To solve the problems above, Huang et al. raised to reasonably select the position of vertical drilling, increase concentration of filling slurry appropriately, or reduce inner diameter of non-trunk pipeline to enhance pipe resistance to ensure the full-bore flow of the pipe. $\mathrm{Wu}$ et al. [25] found out the rheological law of fresh rubber tailing filling slurry by analysis of the ratio of cement to mill tailings, water to cement, and initial temperature condition.

The total tailing high-concentration cemented filling mining method has the advantages of high tailing utilization rate, high concentration, small amount of cementitious materials, difficult stratification and segregation slurry, little dehydration in goaf, relatively low production cost, simple process, and high strength of filling body. Aimed at the problem of test results depending on different operation methods of paddle rheometer, $\mathrm{Wu}$ et al. [26] put forward the slump yield stress theory to correct the above problems, so as to obtain relatively accurate and stable yield stress. Wen et al. [27] studied the rheological properties of slurry with different proportions and different mass fractions through theoretical analysis and laboratory tests. They found out that the increase of shear rate will lead to different model characteristics of the slurry, and the increase of the characteristic particle size will also increase the correlation between rheological parameters and aggregate size. With the raise of mass fraction, this correlation presents different influence directions. It is rare to study the rheological law of tailing filling slurry, and at the same time, consider the strength requirements and production costs of test blocks.

According to the systematic experiment and theoretical analysis, this article studied the rheology rule of the full tailings with high concentration as filling slurry, which provides the reference for the further reasonable solid-to-liquid ratio and layout parameters of the downhole slurry transportation pipe network. It can ensure the safe transport of slurry, the continuity and integrity of filling body in the thermalhydraulic-mechanical coupling behavior, and the strength index of filling body. This research achievement has an important practical significance to guide mine production practice.

\section{Analysis of Particle Size Distribution of Total Tailings}

2.1. Test Materials. The total tailings used in this test come from an iron mine tailing pond in Inner Mongolia, the cementing material is local 42.5 ordinary Portland cement, and the test water comes from city tap water. XRF spectrum was used to analyze the chemical composition of the total tailings, and physical parameters were measured at the same time [28-30]. The physical and chemical properties are shown in Table 1.

The particle size distribution of total tailings analyzed by a laser particle size analyzer is shown in Figure 1, test results of particle size distribution of total tailings are shown in Table 2, and characteristic parameters of particle size distribution of total tailings are shown in Table 3.

2.2. Analysis of Results. From the above test results, $-37 \mu \mathrm{m}$ fine particle content is more than $57 \%$, so it can be seen that the total tailings of the iron mine belongs to the total tailings with very fine particle size. On the one hand, the fine particles in the total tailings are used as fillers between irregular coarse particles, and more importantly, the fine particles are used as lubricating layers between the slurry and conveying pipe walls, which can play a great role in lubrication. Reasonable slurry assembly can minimize the resistance loss of slurry, thus achieving the purposes of improving filling efficiency, slowing down the wear of filling pipes, increasing the service life of pipes, and reducing filling costs.

According to the theory of soil mechanics, when the nonuniformity coefficient of soil particles is greater than 10 and the curvature coefficient is between 1 and 3 , the particle size distribution of soil particles is good, so the total tailing distribution in this test is good. The power exponent of the particle size distribution function fitted by Taboo formula is about 0.3042 , and the Fuller grading index is 0.5 in ideal condition.

\section{Flow Performance Test of Total Tailing High- Concentration Filling Slurry}

3.1. Slump and Expansion Degree Tests. The slump test measures the vertical distance from the upper surface of the slump bucket to the upper surface of the spread slurry by pouring the mixed slurry with a certain cement tailing ratio and mass concentration into the slump bucket at one time and then lifting the slump bucket vertically. The experiment has the characteristics of visually displaying the fluidity of the slurry and being easy to realize. According to the current research status of the high-concentration cemented filling, and the characteristics of the total tailings of the mine, we carry out the slump test of mixed slurry where the ratio of 


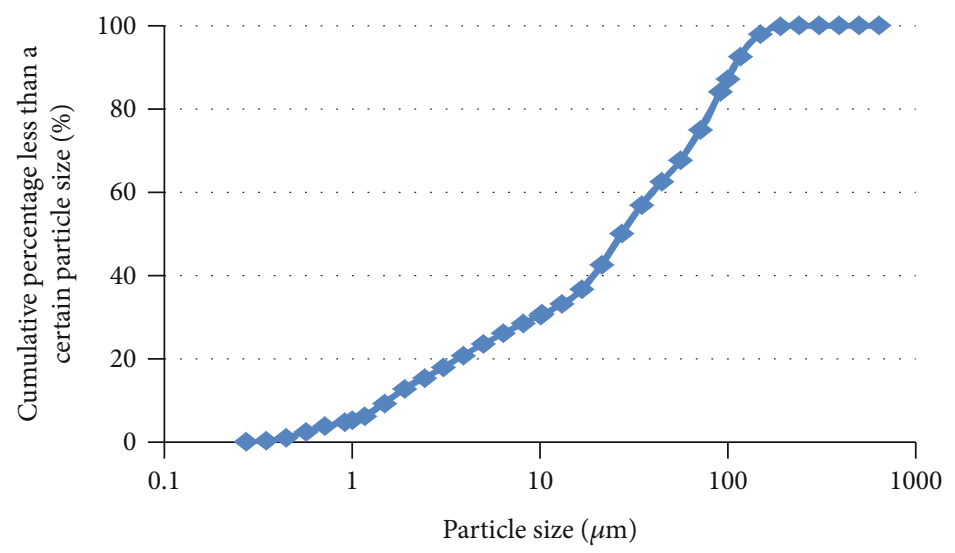

FIgURE 1: Size distribution curve of total tailings.

TABLE 2: Test results of particle size distribution of total tailings.

\begin{tabular}{lcc}
\hline Particle size $(\mu \mathrm{m})$ & $\begin{array}{c}\text { Frequency } \\
\text { distribution }(\%)\end{array}$ & $\begin{array}{c}\text { Negative cumulative } \\
\text { distribution }(\%)\end{array}$ \\
\hline-0.271 & 0 & 0 \\
$0.271 \sim 1.161$ & 6.23 & 6.23 \\
$1.161 \sim 2.403$ & 9.11 & 15.34 \\
$2.403 \sim 4.972$ & 8.14 & 23.48 \\
$4.972 \sim 8.074$ & 4.95 & 28.43 \\
$8.074 \sim 16.70$ & 8.27 & 36.70 \\
$16.70 \sim 34.56$ & 20.27 & 56.97 \\
$34.56 \sim 71.52$ & 18.06 & 75.03 \\
$71.52 \sim 116.10$ & 17.66 & 92.69 \\
$116.10 \sim 240.3$ & 7.31 & 100 \\
\hline
\end{tabular}

cement tailings is $1: 4,1: 6,1: 8,1: 10$, and $1: 12$, and the mass concentration of the slurry is $68 \%, 70 \%, 72 \%, 74 \%$, $76 \%$, and $78 \%$, respectively. 30 groups of mixture were used for the slurry collapse test. The test process is shown in Figure 2.

The slump test results are shown in Table 4. At the same time, the expansion degree of each group of tests is measured, and the arithmetic average of the maximum diameter and the minimum diameter after the slurry are spread out and are taken in the expansion degree test. The test data results are shown in Table 5.

3.2. Analysis of Slump and Expansion Test Results. According to the above slump and expansion tests, the relationship between the concentration and slump, concentration, and expansion of mixed slurry with different cement tailing ratios can be obtained, as shown in Figure 3.

It can be seen from the above figure that, on the whole, the slump of the total tailing mixed slurry decreases gradually with the increase of slurry concentration and cement tailing ratio. However, different concentration intervals and different cement tailing ratio intervals have different decreasing trends. When the concentration is low, the slump of five different cement tailing ratios has little difference, and the maximum difference is only $0.3 \mathrm{~cm}$. With the increase of con- centration, the slump difference of different cement tailing ratios gradually increases, reaching $2.4 \mathrm{~cm}$ at $78 \%$ between the maximum and minimum ratios of cement tailing. Moreover, when the slurry concentration increases from $74 \%$ to $76 \%$, the slump value of all the cement tailing ratios of mixed slurry presents an obvious abrupt change, and the decreasing value of collapse degree increases instantly. Before $74 \%$, the slump of mixed slurry with $1: 12,1: 10,1: 8,1: 6$, and $1: 4$ cement tailing ratios only decreased by $0.90 \%, 0.90 \%$, $1.02 \%, 1.59 \%$, and $2.30 \%$ on average, respectively. When only from $74 \%$ to $76 \%$, the slump decreased by $1.72 \%, 2.41 \%$, $3.81 \%, 3.89 \%$, and $3.62 \%$, respectively. It shows that when the slurry concentration increases from $74 \%$ to $76 \%$, a certain qualitative change has taken place, which leads to the rapid decline of slurry fluidity. The greater the concentration, the greater the influence of the ratio of cement to tailings on slump. Moreover, it can be seen from the figure that this drastic change has begun to show when the concentration is from $70 \%$ to $72 \%$. On the other hand, the slump of mixed slurry with different cement tailing ratios varies with increasing concentration. $1: 12$ decreased by $5.02 \%, 1: 10$ decreased by $7.05 \%, 1: 8$ decreased by $9.06 \%, 1: 6$ decreased by $10.77 \%$, and $1: 4$ decreased by $12.16 \%$. The smaller cement tailing ratio, the less obvious the influence of concentration change on slump.

It can be seen from Figure 4 that, on the whole, the expansion degree of the total tailing mixed slurry gradually decreases with the increase of slurry concentration and cement tailing ratio. However, different concentration intervals and different cement tailing ratio intervals have different decreasing trends. With the increase of the concentration, the difference of the expansion degree of different cement tailing ratios decreases a little bit at first, suddenly increases when the concentration increases from $72 \%$ to $74 \%$, and then gradually decreases. Moreover, when the slurry concentration increases from $74 \%$ to $76 \%$, the decreasing value of the expansion degree of all cement tailing ratio mixed slurry presents an obvious abrupt change, and the decreasing value of expansion degree increases instantly. Before $74 \%$, the diffusivity of $1: 12,1: 10,1: 8,1: 6$, and $1: 4$ mixed slurry of cement and tailings decreased by $4.25 \%, 5.64 \%, 6.36 \%$, $7.36 \%$, and $6.90 \%$, respectively. However, when only from 
TABLE 3: Characteristic parameters of particle size distribution of total tailings.

\begin{tabular}{lcccccccc}
\hline Characteristic parameter & $d_{10} \mu \mathrm{m}$ & $d_{30} \mu \mathrm{m}$ & $d_{50} \mu \mathrm{m}$ & $d_{60}(\mu \mathrm{m})$ & $d_{90}(\mu \mathrm{m})$ & $\mathrm{Cu}$ & Cc & $\begin{array}{c}\text { Characteristic curve of particle } \\
\text { size distribution }\end{array}$ \\
\hline Total tailings & 1.549 & 9.5798 & 27.07 & 39.7826 & 106.7 & 25.6828 & 1.489 & $y=100(d / 24.03)^{0.3042}$ \\
\hline
\end{tabular}

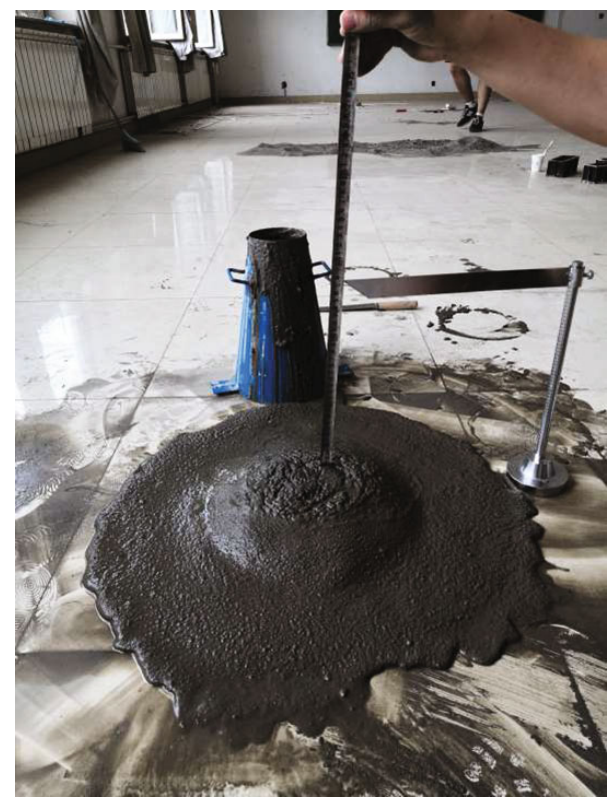

Figure 2: The test process of the slump and expansion degree.

TABLE 4: Slump test results of total tailing mixed slurry (unit: $\mathrm{cm}$ ).

\begin{tabular}{lllllll}
\hline Cement tailing ratio & $68 \%$ & $70 \%$ & $72 \%$ & $74 \%$ & $76 \%$ & $78 \%$ \\
\hline $1: 4$ & 29.6 & 29.1 & 28.3 & 27.6 & 26.6 & 26.0 \\
$1: 6$ & 29.7 & 29.4 & 29.1 & 28.3 & 27.2 & 26.5 \\
$1: 8$ & 29.8 & 29.5 & 29.2 & 28.9 & 27.8 & 27.1 \\
$1: 10$ & 29.8 & 29.5 & 29.3 & 29.0 & 28.3 & 27.7 \\
$1: 12$ & 29.9 & 29.6 & 29.3 & 29.1 & 28.6 & 28.4 \\
\hline
\end{tabular}

TABLE 5: Test results of the expansion degree of total tailing mixed slurry (unit: $\mathrm{cm}$ ).

\begin{tabular}{lcccccc}
\hline Cement tailing ratio & $68 \%$ & $70 \%$ & $72 \%$ & $74 \%$ & $76 \%$ & $78 \%$ \\
\hline $1: 4$ & 117.9 & 111.9 & 106.9 & 95 & 77.5 & 57.5 \\
$1: 6$ & 124.4 & 118.3 & 110.7 & 98.8 & 79 & 63.4 \\
$1: 8$ & 128.6 & 122.5 & 116.6 & 105.5 & 84.5 & 68 \\
$1: 10$ & 133.7 & 127.5 & 121.1 & 112.3 & 92.6 & 71.3 \\
$1: 12$ & 136.5 & 130 & 123.7 & 119.8 & 100.9 & 73 \\
\hline
\end{tabular}

$74 \%$ to $76 \%$, the diffusivity values decreased by $15.78 \%$, $17.54 \%, 19.91 \%, 20.04 \%$, and $18.42 \%$, respectively. It shows that there are some differences when the slurry concentration increases from $74 \%$ to $76 \%$, which makes the fluidity of slurry decrease rapidly. The greater the concentration, the greater the influence of the change of cement tailing ratio on the expansion degree. Moreover, it can be seen from the figure that this drastic change has begun to appear when the concentration is from $70 \%$ to $72 \%$. On the other hand, mixed slurries with different ratios of cement tailings have different change ranges of expansion degree due to the increase of concentration. 1:12 decreased by $46.5 \%, 1: 10$ decreased by $46.7 \%, 1: 8$ decreased by $47.1 \%, 1: 6$ decreased by $49.0 \%$, and $1: 4$ decreased by $51.2 \%$. The greater the ratio of cement tailings, the more severe the influence of concentration change on the expansion degree.

\section{Test on Pipeline Transportation Characteristics of High-Concentration Filling Slurry with Total Tailings}

4.1. Test Instruments and Materials. The NXS-11B rotary viscometer is used in the test. The device dips the inner cylinder connected to the rotor and rotating with it synchronously into the slurry to be measured, adjusts the knob to change the inner cylinder speed so as to change the shear rate, and the torque of the material to the rotor is transferred to the movable frame. When the torque of the measuring spring is the same as this torque, the dial stabilizes at a certain value, the deflection angle is read out by the dial, and then, the viscosity value of the measured slurry is obtained according to the relevant formula. The inner diameter of the outer cylinder is $4 \mathrm{~cm}$, the outer diameter of the inner cylinder is $3.177 \mathrm{~cm}$, the height of the inner cylinder is $5 \mathrm{~cm}$, and the sample consumption is $60 \mathrm{ml}$.

4.2. Test Scheme. The ratio of prepared cement tailing is $1: 4$, $1: 6,1: 8,1: 10$, and $1: 12$, respectively, and the mass concentration of slurry is $68,70,72,74,76$, and 78 , respectively. 30 groups of mixed slurry in total were put into the measuring outer cylinder of the viscometer, and the inner cylinder was inserted into the measuring slurry. We increase the rotor speed step by step from 0 gear, read and record the deflection angle after stabilization, make multiple measurements for each group of tests, and take the average value, so as to ensure the reliability of test data. Finally, the apparent viscosity and shear stress at different shear rates are calculated by corresponding formulas and make multiple measurements and average for each group of tests. Finally, the rheological curve is drawn.

4.3. Test Results. The stable flow pattern of the highconcentration slurry belongs to the plastic structural flow, so its rheological model can be described by the Bingham rheological model, and the expression of this rheological model is as follows [30-34]:

$$
\tau=\tau_{0}+\mu \frac{d u}{d y}
$$




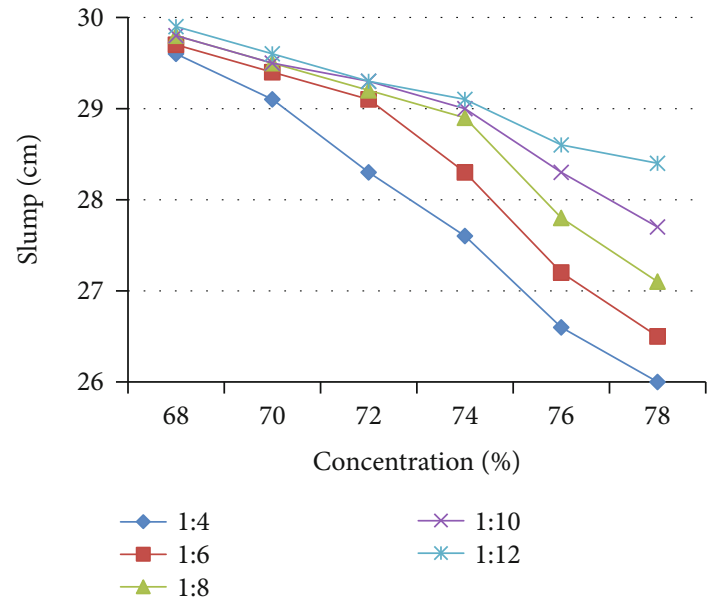

FIgURE 3: Relationship curve between slump and concentration of total tailings mixed slurry.

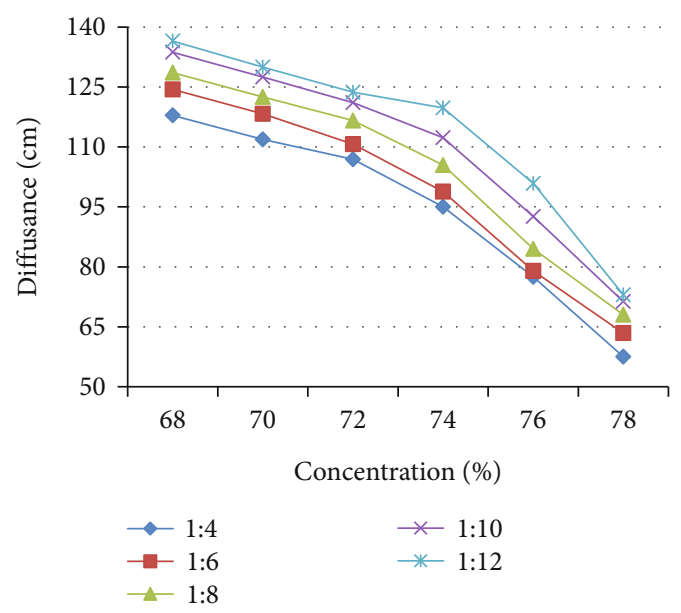

FIGURE 4: Relationship curve between expansion degree and concentration of total tailings mixed slurry.

where: $\tau$-shear stress, $\mathrm{Pa} ; \tau_{0}$-yield stress, $\mathrm{Pa} ; \mu$-plastic viscosity coefficient, Pa.S; and du/dy-shear rate, $\mathrm{S}^{-}{ }^{1}$. We draw rheological curves of shear stress at various shear rates in the test and obtain corresponding yield stress and plastic viscosity coefficient based on them, as shown in Table 6.

4.4. Analysis of Test Results. It can be seen from Figures 5 and 6 that the yield stress and plastic viscosity of each cement tailing ratio increase with the increase of the concentration of mixed slurry, but the increasing speed is different between different concentrations and different cement tailing ratios. For the yield stress, the concentration between $68 \%$ and $72 \%$ has a certain increase, but the increase range is relatively small, especially from $70 \%$ to $72 \%$; the mixed slurry of $1: 4$, $1: 6$, and $1: 8$ has only slight changes, and the yield stress of $1: 4$ is only $31.285 \mathrm{~Pa}$. From $72 \%$ slurry concentration, the yield stress of all cement tailings ratio increased rapidly, and reached the highest when the slurry concentration reached $78 \%$, reaching $60.125 \mathrm{~Pa}, 55.874 \mathrm{~Pa}, 49.741 \mathrm{~Pa}$,
TABLE 6: Test results of rheological parameters with different concentrations and ratio of cement tailing.

\begin{tabular}{|c|c|c|c|}
\hline $\begin{array}{l}\text { Cement tailing } \\
\text { ratio }\end{array}$ & $\begin{array}{c}\text { Concentration } \\
(\%)\end{array}$ & $\begin{array}{l}\text { Yield stress } \\
(\mathrm{Pa})\end{array}$ & $\begin{array}{c}\text { Viscosity } \\
(\mathrm{Pa} \cdot \mathrm{S})\end{array}$ \\
\hline \multirow{6}{*}{$1: 4$} & 68 & 18.779 & 0.0293 \\
\hline & 70 & 29.797 & 0.0377 \\
\hline & 72 & 31.285 & 0.1013 \\
\hline & 74 & 51.247 & 0.1108 \\
\hline & 76 & 57.775 & 0.1233 \\
\hline & 78 & 60.125 & 0.1297 \\
\hline \multirow{6}{*}{$1: 6$} & 68 & 16.834 & 0.0255 \\
\hline & 70 & 27.504 & 0.0312 \\
\hline & 72 & 27.73 & 0.0812 \\
\hline & 74 & 46.539 & 0.0955 \\
\hline & 76 & 53.365 & 0.1089 \\
\hline & 78 & 55.874 & 0.1133 \\
\hline \multirow{6}{*}{$1: 8$} & 68 & 15.267 & 0.0204 \\
\hline & 70 & 25.878 & 0.0278 \\
\hline & 72 & 25.267 & 0.0717 \\
\hline & 74 & 38.836 & 0.0847 \\
\hline & 76 & 47.014 & 0.0942 \\
\hline & 78 & 49.741 & 0.0944 \\
\hline \multirow{6}{*}{$1: 10$} & 68 & 13.981 & 0.0179 \\
\hline & 70 & 17.789 & 0.0211 \\
\hline & 72 & 22.846 & 0.0433 \\
\hline & 74 & 34.199 & 0.0616 \\
\hline & 76 & 44.193 & 0.0884 \\
\hline & 78 & 45.647 & 0.0916 \\
\hline \multirow{6}{*}{$1: 12$} & 68 & 12.192 & 0.0138 \\
\hline & 70 & 15.501 & 0.0186 \\
\hline & 72 & 20.336 & 0.0292 \\
\hline & 74 & 31.332 & 0.0501 \\
\hline & 76 & 38.594 & 0.0793 \\
\hline & 78 & 41.707 & 0.0704 \\
\hline
\end{tabular}

45.647 Pa, and $41.707 \mathrm{~Pa}$ at $1: 4,1: 6,1: 8,1: 10$ and $1: 12$, respectively.

It can be seen from Figure 6 that the rapid growth point of plastic viscosity with different cement tailing ratios is earlier than yield stress, and the slurry concentration starts to increase rapidly from $70 \%$, reaching $0.1013 \mathrm{~Pa} \cdot \mathrm{S}$, $0.0812 \mathrm{~Pa} \cdot \mathrm{S}, \quad 0.0717 \mathrm{~Pa} \cdot \mathrm{S}, \quad 0.0433 \mathrm{~Pa} \cdot \mathrm{S}$, and $0.0292 \mathrm{~Pa} \cdot \mathrm{S}$ at $72 \%$, respectively, and continued to increase, reaching $0.1297 \mathrm{~Pa} \cdot \mathrm{S}, 0.1133 \mathrm{~Pa} \cdot \mathrm{S}$, and 0.0944 , respectively, at $78 \%$. The increase of yield stress and plastic viscosity is mainly due to the decrease of water content in the slurry, the increase of friction resistance between particles, the slurry becomes more viscous, and the stress required to make the slurry flow is relatively increased. However, the initial increase is small because the fine particles act as the intermediate layer between the slurry and pipeline to play a certain lubrication role. 


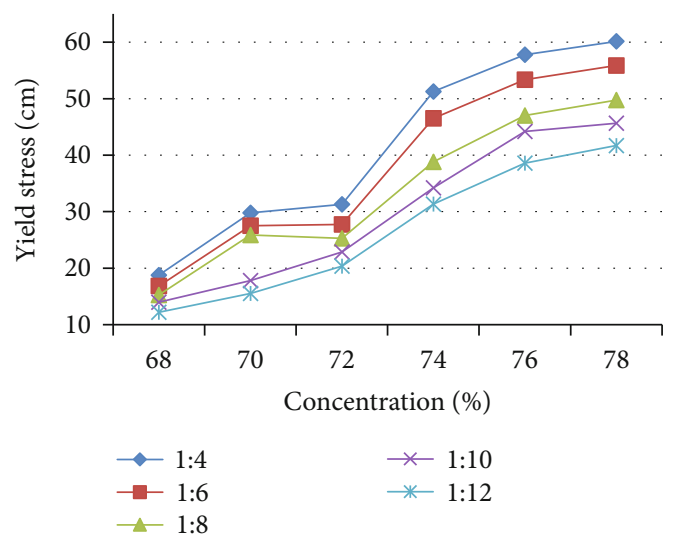

FIGURE 5: Relationship curve between yield stress and concentration of mixed slurry with different cement tailing ratios.

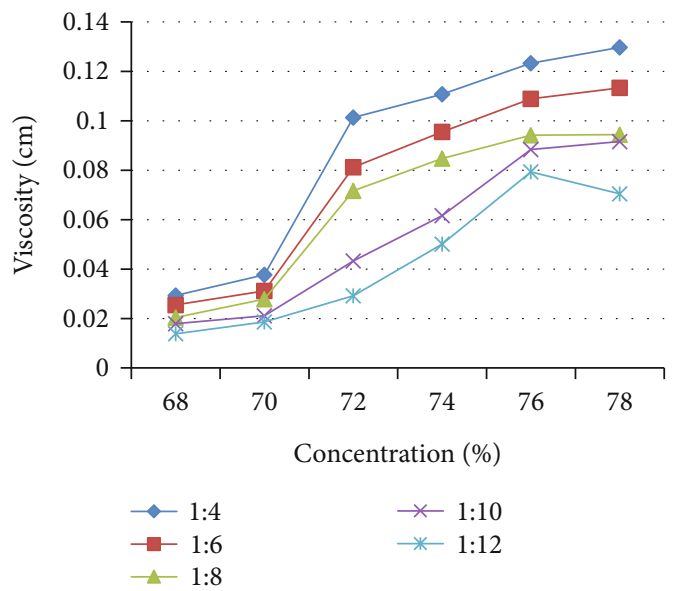

FIGURE 6: Relationship curve between plastic viscosity coefficient and concentration of mixed slurry with different cement tailing ratios.

\section{Strength Test of Filling Body of High- Concentration Filling Slurry with Total Tailings}

5.1. Test Scheme. The ratio of prepared cement tailings is $1: 4$, $1: 6,1: 8,1: 10$, and $1: 12$, respectively, and the mass concentration of slurry is $68,70,72,74,76$, and 78 , respectively. 30 groups of mixed slurry in total were put into a plastic test mold of $70.7 \mathrm{~mm} \times 70.7 \mathrm{~mm}$ and put in a standard curing box with constant temperature $\left(20^{\circ} \mathrm{C} \pm 1^{\circ} \mathrm{C}\right)$ and humidity ( $\geq 90 \%$ ) for curing. The compressive strength was tested by uniaxial press for 3 days, 7 days, and 28 days, respectively. In order to ensure the preparation of measurement data, each group of tests shall be measured several times and averaged.

5.2. Test Results. Uniaxial compressive strength test data of total tailings high concentration filling slurry is shown in Table 7.

5.3. Analysis of Test Results. The variation relationship of slurry strength with different concentrations and different ratios of cement tailings is shown in the following figure.
TABLE 7: Uniaxial compressive strength test data of total tailing high-concentration filling slurry.

\begin{tabular}{|c|c|c|c|c|c|}
\hline \multirow{2}{*}{$\begin{array}{l}\text { Test } \\
\text { no. }\end{array}$} & \multirow{2}{*}{$\begin{array}{c}\text { Cement tailing } \\
\text { ratio }\end{array}$} & \multirow{2}{*}{$\begin{array}{c}\text { Concentration } \\
(\%)\end{array}$} & \multicolumn{3}{|c|}{$\begin{array}{c}\text { Compressive } \\
\text { strength (MPa) }\end{array}$} \\
\hline & & & $3 \mathrm{~d}$ & $7 \mathrm{~d}$ & $28 \mathrm{~d}$ \\
\hline $1-1$ & \multirow{6}{*}{$1: 4$} & 68 & 1.683 & 2.206 & 3.779 \\
\hline $1-2$ & & 70 & 1.715 & 2.444 & 4.393 \\
\hline $1-3$ & & 72 & 1.994 & 2.798 & 4.463 \\
\hline $1-4$ & & 74 & 2.323 & 3.117 & 4.508 \\
\hline $1-5$ & & 76 & 2.512 & 3.499 & 4.617 \\
\hline $1-6$ & & 78 & 2.669 & 4.206 & 7.527 \\
\hline $2-1$ & \multirow{6}{*}{$1: 6$} & 68 & 1.213 & 2.022 & 2.732 \\
\hline $2-2$ & & 70 & 1.653 & 2.198 & 3.323 \\
\hline $2-3$ & & 72 & 1.812 & 2.576 & 3.725 \\
\hline $2-4$ & & 74 & 1.939 & 2.808 & 3.935 \\
\hline $2-5$ & & 76 & 2.055 & 2.833 & 4.197 \\
\hline $2-6$ & & 78 & 2.369 & 3.951 & 5.878 \\
\hline $3-1$ & \multirow{6}{*}{$1: 8$} & 68 & 1.107 & 1.582 & 2.321 \\
\hline $3-2$ & & 70 & 1.399 & 1.865 & 2.934 \\
\hline $3-3$ & & 72 & 1.443 & 1.912 & 3.005 \\
\hline $3-4$ & & 74 & 1.505 & 1.946 & 3.121 \\
\hline $3-5$ & & 76 & 1.572 & 1.984 & 3.233 \\
\hline $3-6$ & & 78 & 1.898 & 2.454 & 3.905 \\
\hline $4-1$ & \multirow{6}{*}{$1: 10$} & 68 & 0.542 & 0.886 & 1.073 \\
\hline $4-2$ & & 70 & 0.626 & 1.013 & 1.204 \\
\hline $4-3$ & & 72 & 0.693 & 1.121 & 1.554 \\
\hline $4-4$ & & 74 & 0.710 & 1.175 & 1.789 \\
\hline $4-5$ & & 76 & 0.773 & 1.234 & 1.998 \\
\hline 4-6 & & 78 & 1.209 & 1.371 & 2.185 \\
\hline $5-1$ & \multirow{6}{*}{$1: 12$} & 68 & 0.217 & 0.432 & 0.876 \\
\hline $5-2$ & & 70 & 0.330 & 0.589 & 1.044 \\
\hline $5-3$ & & 72 & 0.456 & 0.761 & 1.079 \\
\hline $5-4$ & & 74 & 0.646 & 0.850 & 1.103 \\
\hline $5-5$ & & 76 & 0.669 & 0.925 & 1.268 \\
\hline $5-6$ & & 78 & 0.787 & 1.004 & 1.493 \\
\hline
\end{tabular}

It can be seen from Figure 7 that the strength of each filling slurry test block at $3 \mathrm{~d}, 7 \mathrm{~d}$, and $28 \mathrm{~d}$ ages increases with the increase of concentration and at the same time increases with the increase of cement tailings ratio. For 3-day-old blocks, the slurry concentration increased from $68 \%$ to $70 \%$, and the cement tailing ratio increased rapidly at $1: 6$ and $1: 8$, while others all increased slowly. After $70 \%$, the strength increased steadily, but the final value added at $1: 4$, $1: 6$, and $1: 8$ was higher, while the value added at $1: 10$ and $1: 12$ was relatively lower.

The $7 \mathrm{~d}$ age also shows the same trend as the $3 \mathrm{~d}$ age, the difference is that the increment trend of $1: 4$ and $1: 6$ cement tailing ratio is similar, the increment trend of $1: 10$ and $1: 12$ is similar, and 1:8 is between them. The growth rate of each cement tailing ratio slurry is slow when the concentration is below $76 \%$. After 28 days, the intensity of $1: 4$ and $1: 6$ 


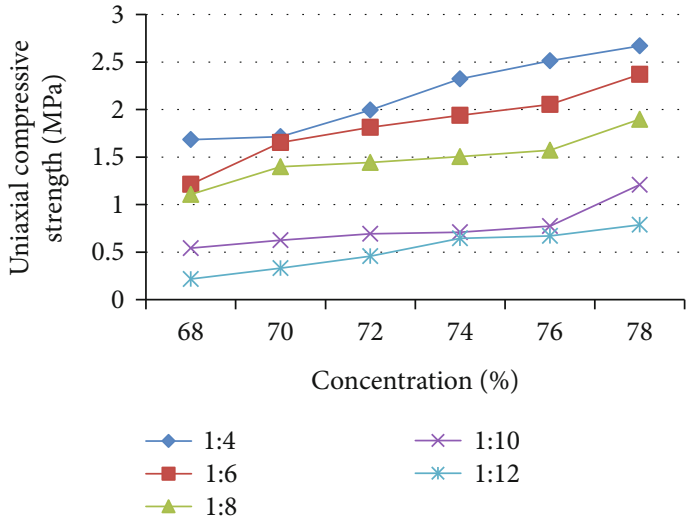

(a)

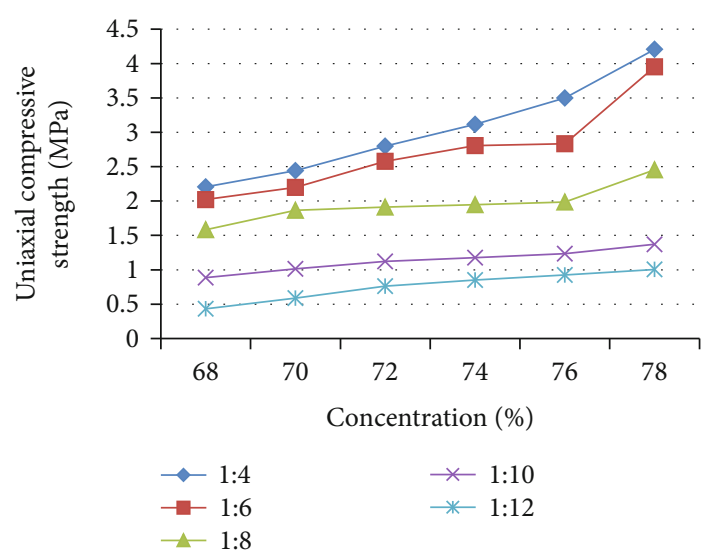

(b)

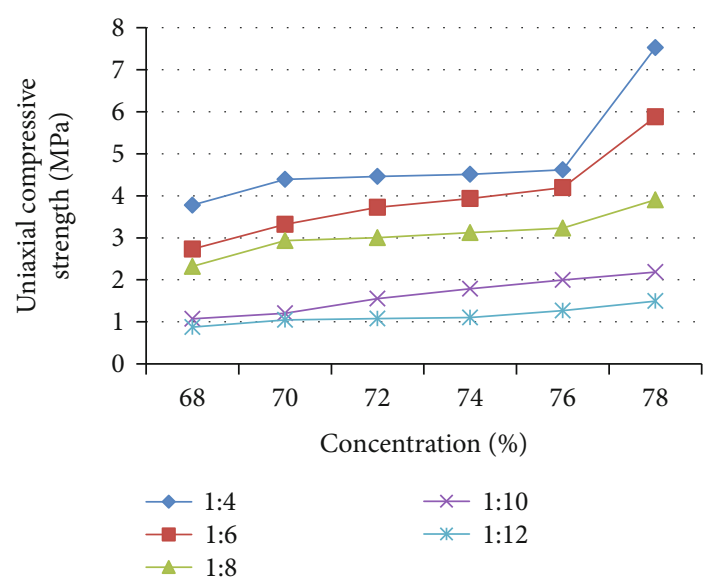

(c)

FIGURE 7: Relationship curve of different cement tailings ratio strength with different concentrations: (a) $3 \mathrm{~d}$, (b) $7 \mathrm{~d}$, and (c) $28 \mathrm{~d}$.

increased from $76 \%$ to $78 \%$, resulting in a big growth mutation, while the intensity of other concentration ranges increased slowly from $70 \%$. When the slurry concentration is $70 \%$, it has reached $4.393,3.323,2.934,1.204$, and $1.044 \mathrm{~Pa}$, respectively.

Considering all previous tests, the mixed slurry concentration tends to be stable when it is about $70 \%$. In this iron mine, the stage-followed filling mining method is adopted to return to the mining room in one step, and the mined- out area is filled with mixed slurry at the same time, and the pillar is mined in two steps, which requires the strength of $2.8 \mathrm{MPa}$ in 28 days. Therefore, the choice of filling slurry with a cement tailing ratio of $1: 8$ and slurry concentration of $70 \%$ to fill the goaf not only meets the requirements of the mine strength but also has good fluidity and is more economical and reasonable.

\section{Conclusions}

According to the particle size distribution test, slump and expansion test, rheological test, and strength test of an iron mine in Inner Mongolia, the following conclusions can be drawn:

(1) The total tailings of an iron mine tailing pond in Inner Mongolia belongs to the filling material of extremely fine particles. On the one hand, fine particles fill in the coarse particles and play the role of linking and filling; on the other hand, fine particles can establish a lubricating layer between filling materials and pipelines to reduce the flow resistance of pipelines, improve filling efficiency, and reduce pipeline wear. The uneven coefficient and curvature coefficient of the total tailings in this mine are 25.6828 and 1.489 , respectively, which are well matched. The power exponent of the particle size grading function fitted by the pot formula is greater than 0.3

(2) The slump and expansion degree of each proportion decrease with the raise of slurry concentration and the cement tailing ratio. The greater the concentration, the greater the influence of cement tailing ratio on slump and expansion degree. Meanwhile, the smaller the cement tailing ratio, the less the influence of concentration on slump and expansion degree. When the slurry concentration of each proportion is between $74 \%$ and $76 \%$, the slump and expansion decrease sharply, and this trend appeared when the slurry concentration is $70 \%$

(3) The yield stress and plastic viscosity of filling slurry with different cement tailing ratios increase with the raise of slurry concentration. The yield stress showed sharp raise when the concentration increased from $72 \%$ to $74 \%$, and the growth rate reached $53.7 \%$ when the ratio was $1: 8$., While the plastic viscosity increased by $72 \%$ and $157.9 \%$ when the ratio was $1: 8$. The enhance of yield stress and plastic viscosity is mainly caused by the decrease of water content in slurry and the increase of friction resistance between particles

(4) The strength of slurry samples filled with different proportions at $3 \mathrm{~d}, 7 \mathrm{~d}$, and $28 \mathrm{~d}$ ages increased with the raise of slurry concentration. In the $3 \mathrm{~d}$ age, the strength of the specimen with ratio of $1: 8$ increased rapidly when the concentration was $70 \%$ at, while that of other specimens increased slowly. Furthermore, the strength of $1: 4,1: 6$, and $1: 8$, and $1: 10$ 
and $1: 12$ showed two rising trend; the former is more obvious. The trend of $7 \mathrm{~d}$ age is similar to that of $3 \mathrm{~d}$ age, and the strength of $28 \mathrm{~d}$ age specimen tends to be stable when the concentration is $70 \%$, and then increased slowly. In consideration of the stage-afterfilling mining methods applied in iron mine adopts, it is economical and reasonable to adopt the ratio of cement-tailings with $1: 8$, the slurry concentration of $70 \%$, and the strength of 28-day test block of $2.934 \mathrm{MPa}$

\section{Data Availability}

All the experimental data are contained in my manuscript and can be referred to.

\section{Conflicts of Interest}

The authors declare that they have no conflicts of interest.

\section{Acknowledgments}

This project was supported by National Key Research and Development Program Funding Project (2018YFC0808403).

\section{References}

[1] C. Zheng, X. Luo, M. Wen et al., “Axial primary halo characterization and deep orebody prediction in the Ashele copperzinc deposit, Xinjiang, NW China," Journal of Geochemical Exploration, vol. 213, p. 106509, 2020.

[2] S. Li, H. Chen, S. Zhang et al., "Validity analysis of geochemical exploration methods for a deep orebody in the Tonglushan skarn $\mathrm{Cu}-\mathrm{Fe}-\mathrm{Au}$ deposit, Hubei Province," Geochimica, vol. 49, no. 2, pp. 205-217, 2020.

[3] C. Lin, Z. Cheng, Z. lv et al., "Characteristics of primary halo zonation and deep ore prediction in Zaozigou Gold Deposit, Gansu Province," Journal of Jilin University. Earth Science Edition, vol. 50, no. 1, pp. 70-84, 2020.

[4] M. Villalba, E. Martha, and M. Kumral, "A value adding approach to hard-rock underground mining operations: balancing orebody orientation and mining direction through meta-heuristic optimization," Journal of Central South University, vol. 26, no. 11, pp. 3126-3139, 2029.

[5] M. N. Bagde and A. G. Sangode, "Numerical study to design stoping operation with sand filling in the case of thick and wide orebody with complex geology," ISRM International Symposium -8th Asian Rock Mechanics Symposium, pp. 1461-1468, 2014.

[6] R. Gorga, "Miscele complesse di minerali grezzi ossidati a smithsonite del giacimento di S. Benedetto (Sardegna sudoccidentale)," ATTI Della Accademia Nazionale Dei Lincei Rendiconti Lincei Scienze Fisiche E Naturali, vol. 14, no. 2, pp. 101-108, 2003.

[7] Y. H. Guo, K. P. Hou, and W. Li, "Numerical optimization of stope structural parameters of complex inclined thin orebody in Mengnuo lead-zinc mine," Electronic Journal of Geotechnical Engineering, vol. 19, no. Z1, pp. 9479-9490, 2014.

[8] M. A. Gurman, L. V. Shcherbak, R. V. Bogomyakov, and E. V. Vylegzhanina, "Mineralogical test and production research of gold mine waste," Journal of Mining Science, vol. 52, no. 5, pp. 974-981, 2016.

[9] M. Adrien Rimélé, R. Dimitrakopoulos, and M. Gamache, “A stochastic optimization method with in-pit waste and tailings disposal for open pit life-of-mine production planning," Resources Policy, vol. 57, pp. 112-121, 2018.

[10] M. L. Smith and R. E. Williams, "Examination of methods for evaluating remining a mine waste site. Part II. Indicator kriging for selective remediation," Engineering Geology, vol. 43, no. 1, pp. 23-30, 1996.

[11] C. Q. Cui, B. Wang, Y. X. Zhao, and L. M. Xue, "Waste mine to emerging wealth: Innovative solutions for abandoned underground coal mine reutilization on a waste management level," Journal of Cleaner Production, vol. 252, 2020.

[12] Y. Taha, M. Benzaazoua, R. Hakkou, and M. Mansori, "Coal mine wastes recycling for coal recovery and eco-friendly bricks production,” Minerals Engineering, vol. 107, pp. 123-138, 2017.

[13] N. Jiang, C. Wang, H. Pan, D. Yin, and J. Ma, "Modeling study on the influence of the strip filling mining sequence on mining-induced failure," Energy Science and Engineering, vol. 8, no. 6, pp. 2239-2255, 2020.

[14] X. F. Wang, D. S. Zhang, C. D. Sun, and Y. Wang, "Surface subsidence control during bag filling mining of super highwater content material in the Handan mining area," Inderscience Publishers, vol. 13, no. 1, pp. 87-102, 2016.

[15] Z. C. Wang, Z. C. Wang, H. C. Xia, and H. F. Wang, "Analysis of hydration mechanism and microstructure of composite cementitious materials for filling mining," Journal Wuhan University of Technology, Materials Science Edition, vol. 32, no. 4, pp. 910-913, 2017.

[16] Y. Wang, Y. X. Lei, and S. Y. Wang, "Green mining efficiency and improvement countermeasures for China's coal mining industry," Frontiers in Energy Research, vol. 8, 2020.

[17] S. F. Wang, L. C. Sun, L. Q. Huang et al., "Non-explosive mining and waste utilization for achieving green mining in underground hard rock mine in China," Transactions of Nonferrous Metals Society of China (English Edition), vol. 29, no. 9, pp. 1914-1928, 2019.

[18] R. Qi, T. Y. Liu, L. Sun, and J. Y. Liu, "Simulating the sustainable effect of green mining construction policies on coal mining industry of China," Journal of Cleaner Production, vol. 226, pp. 3294-3406, 2019.

[19] S. Ro, D. Yan, and S. Kim, "Green mining policy for environmental protection and sustainable development," in IOP Conference Series: Earth and Environmental Science, vol. 474, Sanya, China, 2020, no. 2.

[20] S. Pengde, "Research and application of green filling mining technology for short wall mining in aging mine," in IOP Conference Series: Earth and Environmental Science, vol. 510, 2020, no. 4.

[21] G. J. Sun, P. Wang, T. Feng, W. J. Yu, and J. H. Liu, "Strata movement characteristics of the deep well gangue filling on the fully mechanized mining face," Journal of Mining and Safety Engineering, vol. 37, no. 3, pp. 562-570, 2020.

[22] L. X. Lan, M. Li, Q. Zhang, and Y. Tai, "Experimental study on mechanical properties of solidmixed filling materials in typical mining areas," Journal of Mining and Safety Engineering, vol. 36, no. 3, pp. 593-600, 2019.

[23] V. I. Cheskidov and A. V. Reznik, "Features of hydraulic fill formation in mining water-bearing lignite deposit," Journal of Mining Science, vol. 55, no. 2, pp. 273-279, 2019. 
[24] Y. Huang, X. Duan, Y. Wang, H. Luo, and Y. Hao, "Research on non-full pipeline flow transportation and its prevention of coal gangue cemented backfill, [J/OL]," Coal Science and Technology, pp. 1-7, 2020, http://kns.cnki.net/kcms/detail/11.

[25] W. U. Di, S. J. Cai, and G. Huang, "Coupled effect of cement hydration and temperature on rheological properties of fresh cemented tailings backfill slurry," Transactions of Nonferrous Metals Society of China, vol. 24, pp. 2954-2963, 2014.

[26] A. X. Wu, H. Z. Jiao, H. J. Wang et al., "Yield stress measurements and optimization of paste tailings," Journal of Central South University(Science and Technology), vol. 44, pp. 33703376, 2013.

[27] Z. J. Wen, Q. Gao, Y. D. Wang, and J. Y. He, "Experiment on correlation between rheological properties of filling slurry with different mass concentration and mixed aggregate gradation," Journal of Northeastern University(Natural Science), vol. 41, pp. 642-648, 2020.

[28] Y. L. Zhao, L. Y. Zhang, W. J. Wang, W. Wan, and W. H. Ma, "Separation of elastoviscoplastic strains of rock and a nonlinear creep model," International Journal of Geomechanics, vol. 18, no. 1, article 04017129, 2018.

[29] Y. Wang, H. Zhang, H. Lin, Y. Zhao, and Y. Liu, "Fracture behaviour of central-flawed rock plate under uniaxial compression," Theoretical and Applied Fracture Mechanics, vol. 106, article 102503, 2020.

[30] Y. Zhao, L. Zhang, J. Liao, W. Wang, Q. Liu, and L. Tang, "Experimental study of fracture toughness and subcritical crack growth of three rocks under different environments," International Journal of Geomechanics, vol. 20, no. 8, article 04020128, 2020.

[31] H. Lin, H. Yang, Y. Wang, Y. Zhao, and R. Cao, "Determination of the stress field and crack initiation angle of an open flaw tip under uniaxial compression," Theoretical and Applied Fracture Mechanics, vol. 104, article 102358, 2019.

[32] H. Lin, X. Zhang, Y. Wang et al., "Improved nonlinear Nishihara shear creep model with variable parameters for rock-like materials," Advances in Civil Engineering, vol. 2020, Article ID 7302141, 15 pages, 2020.

[33] Y. Zhao, Y. Wang, W. Wang, W. Wan, and J. Tang, "Modeling of non-linear rheological behavior of hard rock using triaxial rheological experiment," International Journal of Rock Mechanics and Mining Sciences, vol. 93, pp. 66-75, 2017.

[34] X. P. Zhou, Y. H. Zhang, Q. L. Ha, and K. S. Zhu, "Micromechanical modelling of the complete stress-strain relationship for crack weakened rock subjected to compressive loading," Rock Mechanics and Rock Engineering, vol. 41, no. 5, pp. 747-769, 2008. 